The authors wish to express their thanks to Mr. E. S. Dean and Mr. F. 'I'. Downing, who have been associated with them in this research.

Literature.

Ealls, A. K., and Korns, J. H.: Journ. Immunol., Balt., 1918, vol. 3 , pp. 375-387.

Kolmer, J. A.: Infection, Immunity, and Specific Therapy, 1917, p. 74. W.B. Saunders Company, Philadelphia and New York

Thomson, D.: Detoxicated Vaccines, Lancet, June 28th, 1918 ; Detoxi cated Vaccines, Journ. State Medicine, 1921, vol. 29, No. 3; Biochenistr of Germs and otber Proteins, Lancet, April 16th and 23rd, 1921 ; Detoxicated Tubercle Bacillus Vaccine, Brit. Journ. of Tuberculosis, January, $19 \geq 2$.

\section{STRANGULATED DIRECT INGUINAL HERNIA.}

\section{BY}

E. E. HUGHES, Ch.M.ManCh., F.R.C.S.Eng., HONORARY SURGEON, ANCOATS HOSPITAL, MANCHESTER; VISITING SURGEON, MANCBRSTER CHILDREN'S HOSPITAL.

THE formation of a direct inguinal hernia is due, in the majority of cases, to repeated distension of a weak point in the posterior wall of the inguinal canal. In such cases the abnormal opening in the abdominal wall is usually large, and the edges of the opening offer little resistance to the protrusion of bowel or omentum within the hernial sac. Occasionally, however, when the intra-abdominal pressure is suddenly increased, the weak point in the posterior wall of the inguinal canal undergoes instant rupture, and it is in these cases that strangulation is apt to occur.

In the case to be described the strangulation was probably caused simultaneously with the origin of the hernia-that is to say, a split occurred in the medial portion of the posterior wall of the inguinal canal (conjoined tendon) which allowed of the protusion of a knuckle of gut-covered, of course, by a layer of parietal peritoneum -into the inguinal canal: The tension of the conjoined tendon tended to approximate the edges of the split and thus prevented the reduction of the hernia and also imperilled the blood supply of the herniated gut, producing its strangulation. Strangulation of a direct inguinal hernia is an event of somewhat uncommon occurrence, and the following case, which was recently under my care, may be regarded as a fairly typical example of this condition.

The patient, a carter, aged 62, was admitted as an urgency case under my care at the Ancoats Hospital, complaining of a painful swelling in the right groin. He stated that, about eight hours previously, whilst loading a cart, he felt a sudden pain in the lower part of his abdomen. At first he endeavoured to disregard the pain, but as it did not disappear he left his work and returned home. Here he noticed a swelling in the right groin, and on going to his doctor was advised to seek treatment immediately at to his doctor was advised to seek treatment immediately at Ancoats Hospital. He gave a previous history of a hernia which was easily reducible, on the left side,
had never been one on the right side.

had never been one on the right side.
On examination the patient was a fairly muscular man, but looked decidedly ill. Over the inner third of Poupart's ligament on the right side there was a ronnded tender swe!ling, tense, elastic, quite free above and below, and apparently not communicating with the internal abdominal ring. There was no impulse on coughing, and gentle taxis failed to have any effect ou its reduction.

On the left side there was an easily reducible direct inguinal hernia. Operation was immediately carried out. The inguinal canal was opened by division of skin and external oblique aponeurosis. The hernial sac at once presented itself, and on isolation was found to be entirely free from, and external to, the spermatic cord. The neck of the sac was traced to the conjoined tendon. The sac, which was extremely thin, was then opened. A quantity of the usual blood-stained peritoneal fluid escaped, and a knuckle of bovel of the Richter type, and plum-coloured, was aeen. Digital examination of the neck of the sac from within seen. Digital examination of the neck of the sac from within tendon. A hernia director was passed within the sac, and the tendon was divided in a medial direction. The gut was drawn out of the abdominal cavity, found to be viable, and then reduced. An attempt at a radical cure for the hernia was male by ligaturing the sac, suturing the split in the conjoined tendon, and then suturing the internal oblique muscle to Poupart's ligament.

The patient made an uninterrupted recovery, and was discharged from bospital seventeen days alter admission.

THE Fifth Italian Congress for Industrial Diseases will be held at Florence from June 11th to $14 \mathrm{th}$, when the following subjects will be discussed: (1) Rural hygiene since the war, especially in relation to malaria, introduced by Professor A. Monti ; (2) new and old views on lead poisoning, introduced by Professor C. Biondi ; (3) reform of legislation relating to industrial accidents, introduced by Professor Borri ; (4) prevention of disabilities following disease, introduced by Professor L. Devoto. An exhibition will be held illustrating the most recent methods for preventing industrial accidents.

\section{ftemoranda:}

\section{MEDICAL, SURGICAL, OBSTETRICAL.}

\section{TUBERCULOUS PERICARDITIS.}

Medical literature contains so few references to tuberculous pericarditis that I feel justified in recording the case mentioned below as being of interest.

A student, aged 23, who had arrived in England for the first time eighteen months previously from a colony, was admitted to the hospital of SS. John and Elizabeth on A w was admitted to a history of having taken to bed for a w April 13th, 1921, with a history of having taken to bed for a week with marked malaise
and rise of temperature. There were no other symptoms what-
ever. He had always enjoyed excellent health, and had never ever. He had always enjoyed excellent health, and had never
suffered from any pulmonary complaint. On admission his temperature was $103.6^{\circ} \mathrm{F}$., pulse rate 120 , and respiration rate 40 He was tall, thin, and of a pallid complexion. His breathing, though rapid, was unembarrassed. The tongue was clean.

On examination the right side of the chest was almost motionless and dull from the fourth rib down chest was almost motionwas almost absent. Breath sounds were prolonged and high-pitched was almost absent. Breath sounds were prolonged and high-pitched above and practically absent below the fourth rib. The apex beat
of the heart was displaced to the left, and an exocardial to-and-fro of the heart was displaced to the left, and an exocardial to-and-fro
murmur was heard. Aspiration of the right chest yielded 20 ounces of clear fluid, which on microscopic examination showed neither cells nor bacilli, and on culture this remained sterile. A diagnosis of pleural and pulmonary tuberculosis was made.

'The murmur at the cardiac apex became more marked as time progressed, and seemed rougher and louder on expiration, and on May 19th some tine crepitations were heard in the right midaxillary line, both on inspiration and expiration. These extended anteriorly on the 31 st, when a very marked rough creaking pleural rub was also heard over the left base anteriorly. Night sweats at this date became very marked. Repeated examination of the sputum revealed no tubercle bacilli. The cardiac area of dullness appeared to increase gradually to the left and right, and on June 6 th the exocardial murmur, which had been getting less audible, disappeared, and at the same time the heart sounds became less distinct. Breath sounds in the left mammary region were now harsh, and in the right scapular region almost tubular in character and accompanied by fine crepitations. Emaciation became more marked. Tuberculous pericarditis was now

became mor

$X$-ray examination on June 16 th showed an enormous cardiac shadow, and loss of pulsation; this was suggestive of pericardial effusion. Paracentesis pericardii was performed on three occasions with obvious relief to the patient. The fluid obtained, altogether 8 ounces, was sanious in character, and sterile in direct films and culture. No tubercle bacilli were detected." The right base was also aspirated and a similar fluid obtained, which right base was also aspirated and a similar fluid obtained, which was
shown to be sterile bacteriologically. The patient died on July lst. During bis illness the temperature was continued for the first ten days; subsequently it was intermittent, ranging between $97^{\circ}$ and $102^{\circ} \mathrm{F}$.; the pulse rate varied between 90 and 140 , respirations from 18 to 35 .

Post-mortem Examination.-The body showed extreme wasting. On opening the chest the parietal pericardium was found to be very thickened, in parts up to a quarter of an inch, and was fused with the thickened visceral pleura. The visceral pericardium was markedly thickened by a deposit of caseous material to the extent of half an inch. The pericardial cavity was dilated and contained of half an inch. The pericardial cavity was dilated and contained
approximately 8 ounces of sanious fluid. The beart muscle $\$$ was very pale and flabby; the valves were competent. The pleuras were thickened and contained some free fluid; and the lungs, which were adherent to these in parts, especially on the left, showed numerous miliary tubercles, but practically no evidence of old tuberculosis. The mediastinal glands showed moderate enlargement. The liver, spleen, and kidneys showed amyloid degeneration; the latter had a few miliary tubercles, and the degeneration; the latter had a few miliary tubercles, and
peritoneum was studded witb these. Free fluid was present.

For kind permission to publish this case I am greatly indebted to Dr. A. Saunders, Physician to the Hospital of SS. John and Elizabeth.

F. Joselin JaUCh, M.R.C.S.Eng., L.R.C.P.Lond., Resident Medical Offcer, Hospital of SS. John and Elizabeth, London.

\section{REFERENCE.}

Adrien Forestier: " Études Cliniques de la Péricardite Tubercu'euse avec attein te des autres Séreuses."

\section{RUPTURED HEART.}

The following case seems to me of sufficient interest to place on record, as it illustrates how a fatal result may follow a ver slight effort in a person who was not apparently seriously ill. her chief complaint being of shortness of breath.

On January 10th, 1922, I was called hastily and found a fairly well nourished woman lying on her back on a bed. She was guit dead. The only person in the house besides the dead woman.was her husband. He said his wife was about 50 years of age, wä almost a teetotaler, and had never been really ill before, but a few months ago had had an upset and had lately complained of shortnes of breath. On this particular day, not feeling very well, she stay.ed in bed; during the morning he heard a noise as of someone falling, 